\title{
Microencapsulation of single, multiple, and zona pellucida-free mouse preimplantation embryos in sodium alginate and their development in vitro
}

\author{
N. C. Cosby and W. R. Dukelow \\ Endocrine Research Center, Michigan State University, East Lansing, MI 48824, USA
}

\begin{abstract}
Summary. Preimplantation embryos obtained from immature superovulated B6D2F1 female mice were microencapsulated in sodium alginate singly, in multiples of 2 or 3 , or denuded of their zona pellucida. Encapsulated embryos developed in vitro at a rate similar to control embryos. Development of zona pellucida-free embryos was significantly less than that of intact embryos, but there was no difference between encapsulated and non-encapsulated zona pellucida-free embryos. Development of 2- and 4-cell embryos in sodium alginate was independent of cell stage. This report demonstrates the usefulness of a viable, biodegradable embedding material for the microencapsulation of manipulated preimplantation mammalian embryos.
\end{abstract}

Keywords: embryo; microencapsulation; sodium alginate; zona pellucida; mouse

\section{Introduction}

Two reports on embedding manipulated mammalian embryos for subsequent transfer to recipient females relate to bisected, post-compaction blastocysts of cows and bisected 2-cell embryos of sheep. The former were transferred in $7 \%$ gelatin which proved of no enhanced or detrimental effect to further development. The latter were transferred in agar chips and then were removed surgically at a later stage. Willadsen (1979) has embedded split sheep embryos (2-cell) in agar chips, transferred them to recipient ewes, and produced live, monozygotic twins. The purpose of embedding in this experiment was protection of the embryo for the cut zona pellucida of the split embryo. Warfield et al. (1987) embedded split cow embryos (blastocyst, postcompaction) in $7 \%$ gelatin, and transferred them to recipient cows which were assessed for pregnancies at a later time. The embedding was to assess the need for protection of the embryos after zona splitting.

Lim \& Sun (1980) developed a technique to encapsulate living cells in a sodium alginate-calcium chloride matrix and this method has been adapted to give quicker degradation in vivo (Adinaya, 1987). Alginic acid is a polysaccharide derived from brown seaweed and is composed of three (1-4)-linked polyuronic acid blocks consisting of poly-beta-D-mannuronic acid segments, poly-alpha-L-guluronic acid segments, and segments alternating in the above two moieties. The saccharide chains, in the sodium form of free acid groups (sodium alginate), cross link when calcium chloride is added. The divalent calcium ion displaces two monovalent sodium ions to cross link the polymer (Adinaya, 1987).

The goals of our study were to: (1) microencapsulate 2- and 4-cell mouse embryos in sodium alginate, (2) determine whether several encapsulated embryos would develop in vitro at a rate similar to those embedded singly; and (3) determine whether zona pellucida-free, precompacted encapsulated embryos would develop in vitro at a rate comparable to denuded and whole embryos. 


\section{Materials and Methods}

Animals. The animals used were a hybrid strain of mouse, B6D2F1 (a cross of C57BL/6J by DBA/2J mice). The original strains were purchased from The Jackson Laboratory (Bar Harbor, ME, USA); subsequently, our own breeding programmes maintained stocks of $\mathrm{C} 57 \mathrm{BL} / 6 \mathrm{~J}$ and DBA/2J animals. Mice were provided with $\mathrm{Breeder}$ Blox ${ }^{\circledR}$ (Wayne Feeds, Inc., Bartonville, IL, USA) and water ad libitum, and maintained in a $12 \mathrm{~h}$ light: $12 \mathrm{~h}$ dark cycle (lights on $08: 00 \mathrm{~h}$ ).

Superovulation. When they were 21-25 days of age, B6D2F1 mice were superovulated by injection (s.c.) with 5 or 8 i.u. PMSG (Serotropin ${ }^{\circledR}$, Teizo, Tokyo, Japan), followed by 5 or 8 i.u. hCG (Sigma Chemical Co., St Louis, MO, USA), respectively (Cosby et al., 1989) 48-51 h later. Immediately after hCG injection, the females were housed with males of proven fertility overnight at a ratio of $1: 1$.

Medium. The medium used for collection and culture of embryos was Tyrode's-albumin-lactate-pyruvate (TALP) adapted for the mouse. The buffer, $N$-2-hydroxyethyl-piperazine- $N^{\prime}$-2-ethanesulphonic acid (Hepes), was added to the TALP for collecting procedures. TALP was adapted from a medium used for hamster embryo culture (Bavister et al., 1983). The medium was adapted in the following manner: no amino acids were included because preimplantation mouse embryos require only the energy substrates lactate, pyruvate and glucose (Cholewa \& Whitten, 1970; Whittingham, 1971; Hogan et al., 1986), and penicillin/streptomycin (Sigma; $10000 \mathrm{IU} / 100 \mathrm{ml}$ ) was added to working aliquants of medium.

TALP was prepared from a stock solution of $114.0 \mathrm{~mm}-\mathrm{NaCl}, 3.2 \mathrm{~mm}-\mathrm{KCl}, 2.0 \mathrm{~mm}-\mathrm{CaCl}_{2} .2 \mathrm{H}_{2} \mathrm{O}, 0.5 \mathrm{~mm}-$ $\mathrm{MgCl}_{2} \cdot 6 \mathrm{H}_{2} \mathrm{O}, 0 \cdot 4 \mathrm{mM}-\mathrm{NaH}_{2} \mathrm{PO}_{4} \cdot \mathrm{H}_{2} \mathrm{O}, 5.0 \mathrm{~mm}$-glucose, 10000 i.u. penicillin-G/100 ml, and $1.0 \mathrm{mg}$ phenol red $/ 100 \mathrm{ml}$. A working solution of $100 \mathrm{ml}$ was prepared by adding sodium lactate (to $10 \mathrm{~mm}$ ), $\mathrm{NaHCO}_{3}(25 \mathrm{~mm})$ and $10000 \mathrm{i} . \mathrm{u}$. penicillin/streptomycin (Sigma) to the salt solution $24 \mathrm{~h}$ before each experiment. The solution was filtered through a $0.22 \mu \mathrm{m}$ Corning sterile filter system (Corning Glass Works, $\$ 25983$, Corning, NY, USA), and placed in the incubator for equilibration overnight. On the day of the experiment, sodium pyruvate $(0.5 \mathrm{~mm})$ and $300 \mathrm{mg}$ BSA were added to the $100 \mathrm{ml}$ solution.

Embryo collection. At 48 and $72 \mathrm{~h}$ after injection of hCG, the mice were killed by cervical dislocation, the oviducts excised and embryos recovered in $0.5 \mathrm{ml}$ TALP-Hepes. Embryos were picked up with a micropipette attached to a thumb-screw aspirator. A similar aspirator was used with a $100 \mu \mathrm{l}$ micropipette for encapsulated embryo manipulations. The embryos were washed once in $0.5 \mathrm{ml}$ fresh TALP-Hepes, pooled in $1.0 \mathrm{ml}$ TALP-Hepes in a Falcon tissue culture dish (Beckton Dickinson and Co., $\$ 3037$, Cockeysville, MD, USA) and placed in the incubator at $37^{\circ} \mathrm{C}$ in $5 \%$ $\mathrm{CO}_{2}$ /air. Upon collection all embryos (minimum 2 animals per trial) were allocated randomly to control or treatment groups. Embryo collection (and encapsulations) were carried out under a dissecting microscope.

Chemical digestion. Zonae pellucidae were digested chemically using acid-Tyrode's solution. Embryos were aspirated from the collecting medium, and extruded into the solution of acid-Tyrode for approximately 20-30 sec or until the zona pellucida began to disappear. Denuded embryos were then washed in fresh medium once before further treatment.

Microencapsulation. Sodium alginate (Sigma, type IV) was prepared on the day of experimentation by suspending $0.22 \mathrm{~g}$ in $20.0 \mathrm{ml} 0.15 \mathrm{M}-\mathrm{NaCl}$ to yield a $1.1 \%$ solution. Similarly, $0.30 \mathrm{~g} \mathrm{CaCl}_{2}$ was dissolved in $20.0 \mathrm{ml} 0.15 \mathrm{M}-\mathrm{NaCl}$ to yield a $1.5 \%$ solution. These solutions were kept at $37^{\circ} \mathrm{C}$ on a slide warmer. The saline was filter sterilized through a $0.22 \mu \mathrm{m}$ filter disk. Microencapsulation was performed by aspirating embryos into an acid-washed, sterilized 5- $\mu \mathrm{l}$ glass micropipette along with $1.0 \mu \mathrm{l}$ medium, extruded into the sodium alginate (SA) solution, mixed lightly to ensure even alginate envelopment, and re-aspirated in the order SA-embryo-SA for a total volume approximating $1.0 \mu \mathrm{l}$. The contents of the micropipette were expelled under the $\mathrm{CaCl}_{2}$, resulting in immediate gelling of the matrix into a plug. The $\mathrm{CaCl}_{2}$ solution was agitated slightly for $30 \mathrm{sec}$ to allow adequate cross-linking of divalent calcium ions in the alginate matrix. A larger (inner diameter) micropipette was then used to aspirate the encapsulated embryos from the $\mathrm{CaCl}_{2}$ solution into $1.0 \mathrm{ml}$ of fresh TALP-Hepes to wash the excess calcium ions from the plug. A 3-welled embryological watchglass facilitated the sequential transfers. After washing, the plug was transferred and expelled into a culture dish containing $1.0 \mathrm{ml}$ TALP, covered with light mineral oil, and placed in the incubator. Cleavage stages of the control and encapsulated embryos were assessed at 24 or $48 \mathrm{~h}$ on a Nikon Diaphot inverted microscope. Criteria for satisfactory development were as described by Hogan et al. (1986). In $24 \mathrm{~h}$ a normally developing 2-cell mouse embryo will be an 8-cell and a 4 -cell will be a compacted morula. For $48 \mathrm{~h}$, satisfactory development was scored when 4-cell embryos became blastocysts. All embryos were scored by the same researcher.

In Exp. I embryos were encapsulated singly and cultured in groups of 5 or 6 in TALP under oil for $24 \mathrm{~h}$, and control embryos were cultured in groups of 5 or 6 under like conditions.

In Exp. II embryos were encapsulated singly, doubly or triply in a given volume of alginate, and cultured in vitro. One capsule of one embryo, one capsule of 2 embryos and one capsule of 3 embryos were then cultured together in TALP under oil for $24 \mathrm{~h}$. Control embryos were cultured in groups of 6 in TALP under oil.

In Exp. III, 4-cell embryos were denuded of the zona pellucida in acid-Tyrode's solution. Subsequently, denuded embryos were treated as in Exp. I for encapsulation and culture. Control trials included denuded and cultured, encapsulated and cultured, and cultured-only embryos. A minimum of 2 females per trial over 6 trials was used 
Statistical analyses. Statistical analytic methods were taken from Gill (1978). Encapsulation versus control trials were analysed using factorial contingency tables. Multiple encapsulated embryo trials were analysed using multidimensional contingency tables to test for independence and/or interaction of cell stage and embryo number per capsule. As the $q$ value for the test of independence was low, an approximate $q$ value for interaction was used. The $q$ value for interaction was also low, therefore cell stage data were pooled and comparisons for number of embryos per capsule were made. Trials involving the chemical removal of the zona pellucida and encapsulation were analysed by factorial $\chi^{2}$ tests for factors and interaction.

\section{Results}

\section{Experiment I: effect of encapsulation on development}

The results are shown in Table 1. Factorial analysis of the data showed the developmental rate to be independent of cell stage, treatment, and interaction of the two factors. Representative encapsulated embryos are shown in Fig. 1.

Table 1. Developmental rate of encapsulated and control B6D2F 1 embryos by cell stage

\begin{tabular}{lcc}
\hline & \multicolumn{2}{c}{ Developmental rate } \\
\cline { 2 - 3 } Embryo & Encapsulated (\%) & Control (\%) \\
\hline 2-cell & $40 / 97(41 \cdot 2 \%)$ & $65 / 123(52 \cdot 8 \%)$ \\
4-cell & $24 / 39(61 \cdot 5 \%)$ & $18 / 31(58 \cdot 1 \%)$ \\
Total & $64 / 136(47 \cdot 1 \%)$ & $83 / 154(53 \cdot 9 \%)$ \\
\hline
\end{tabular}

\section{Experiment II: effect of microencapsulating several embryos in one capsule}

In some trials, 2 capsules of 2 embryos were included; therefore, 8 control embryos were cultured together. As shown in Table 2 there was no interaction and independence of cell stage and number of embryo(s) per capsule on development. Statistical analysis (Bonferroni $\chi^{2}$ ) showed no difference in multiple encapsulated embryo number $(P>0.05)$. Analysis of the control embryos confirmed the results obtained in Exp. I.

Table 2. Developmental rate of $\mathrm{B} 6 \mathrm{D} 2 \mathrm{~F} 1$ embryos by cell stage per capsule

\begin{tabular}{lccccc}
\hline & & \multicolumn{4}{c}{ Treated } \\
\cline { 3 - 6 } $\begin{array}{l}\text { Embryo } \\
\text { stage }\end{array}$ & \multicolumn{1}{c}{$\begin{array}{c}1(\%) \\
\text { embryos }\end{array}$} & $\begin{array}{c}2(\%) \\
\text { embryos }\end{array}$ & $\begin{array}{c}3(\%) \\
\text { embryos }\end{array}$ & Total (\%) \\
\hline 2 -cell & $52 / 57(91 \cdot 2)$ & $7 / 9(77 \cdot 8)$ & $16 / 22(72 \cdot 7)$ & $12 / 24(50)$ & $35 / 55(63 \cdot 6)$ \\
4 -cell & $18 / 24(75)$ & $3 / 4(75)$ & $10 / 10(100)$ & $11 / 15(73 \cdot 3)$ & $24 / 29(82 \cdot 8)$ \\
Total & $70 / 81(86 \cdot 4)$ & $10 / 13(76 \cdot 9)$ & $26 / 32(81 \cdot 3)$ & $23 / 39(59)$ & $59 / 84(70 \cdot 2)$ \\
\hline
\end{tabular}

\section{Experiment III: effect of encapsulation of zona pellucida-free embryos}

The developmental rate of the encapsulated group was comparable to that of the control group (Table 3). Likewise, zona pellucida-free and encapsulated embryos developed at a rate similar to that of zona pellucida-free only embryos. However, zona pellucida-free embryos developed at rates significantly $(P<0.001)$ lower than those of intact embryos. Statistical analysis showed no difference between encapsulated and non-encapsulated embryos, nor was there an interaction between encapsulation of the embryo and presence of a zona pellucida. 
Table 3. Developmental rate of $\mathrm{B} 6 \mathrm{D} 2 \mathrm{~F} 1$ embryos after chemical removal of the zona pellucida with subsequent encapsulation and culture, or culture only

\begin{tabular}{lc}
\hline Trial & $\begin{array}{c}\text { Developmental } \\
\text { rate }(\%)\end{array}$ \\
\hline Control & $57 / 60(95)$ \\
Encapsulated & $20 / 20(100)$ \\
Zona pellucida-free & $14 / 20(70)$ \\
Zona pellucida-free/encapsulated & $11 / 20(55)$ \\
\hline
\end{tabular}

\section{Discussion}

Mouse preimplantation embryos microencapsulated in a sodium alginate-calcium chloride matrix can be cultured in vitro to further stages of development. A technique to encapsulate the embryos was adapted which can be accomplished easily with standard collecting apparatus. Any number of embryos may be encapsulated together with this technique. This study demonstrated that up to 3 preimplantation mouse embryos may be encapsulated together with rates of development comparable to those of single embryos in vitro. Finally, preimplantation mouse embryos chemically denuded of the zona pellucida and subsequently encapsulated in alginate develop in vitro comparably to zona pellucida-free embryos.

Various methods of microencapsulating mouse embryos were attempted in an effort to develop a feasible and consistent technique. The method used, adapted from Adinaya et al. (1987), allows for the precise control of capsule diameter and less precise control of capsule length. Once this method was employed, no embryos were lost in the encapsulating process, indicating its relative ease and repetitive nature.

The results presented show independence of encapsulation on development. Embryos at the 2- and 4-cell stage developed just as well as the control embryos, and there was no statistical difference between cell stages. The overall developmental rate for encapsulated embryos (Table 1) was $47 \cdot 1 \%$ compared to $53.9 \%$ for control embryos. These numbers reflect suboptimal culture conditions in early trials and the increased embryo developmental rate in culture in later trials was seen across treatments. The culture conditions were suboptimal as developmental rates for control embryos in Exps II and III ranged from 75 to $95 \%$ whereas the developmental rate in Exp. I was only $53.9 \%$. The fact that the rate of embryo development for treatment and control groups was not significantly different, even though both were lower than expected, substantiates a negative influence inherent in both treatments.

The results of multiple embryo microencapsulation (Exp. II) in general agree with the previous encapsulation trials as all developmental rates were greater than $50 \%$. These data show that embryos encapsulated as 2 or 3 together, will develop equally as well as a single encapsulated embryo. These results indicate that the calcium-alginate matrix may be used to encapsulate any number of preimplantation embryos for various in-vitro studies or for multiple in-vivo transfers.

Pilot trials with zona pellucida-free embryos in Swiss Webster white mice (data not shown) indicated that denuded, encapsulated embryos developed at rates in vitro comparable to those of embryos from which only the zona pellucida had been removed. Developmental rates of B6D2F 1 embryos denuded compared to denuded and encapsulated embryos demonstrated no statistical difference although denuded embryos showed poor development in comparison to intact embryos.

As previous work (Willadsen, 1979; Warfield et al., 1987) has demonstrated the viability of bisected and embedded mammalian embryos, there remains little doubt of the application of sodium alginate microencapsulation to manipulated mouse embryos as well as other species. 

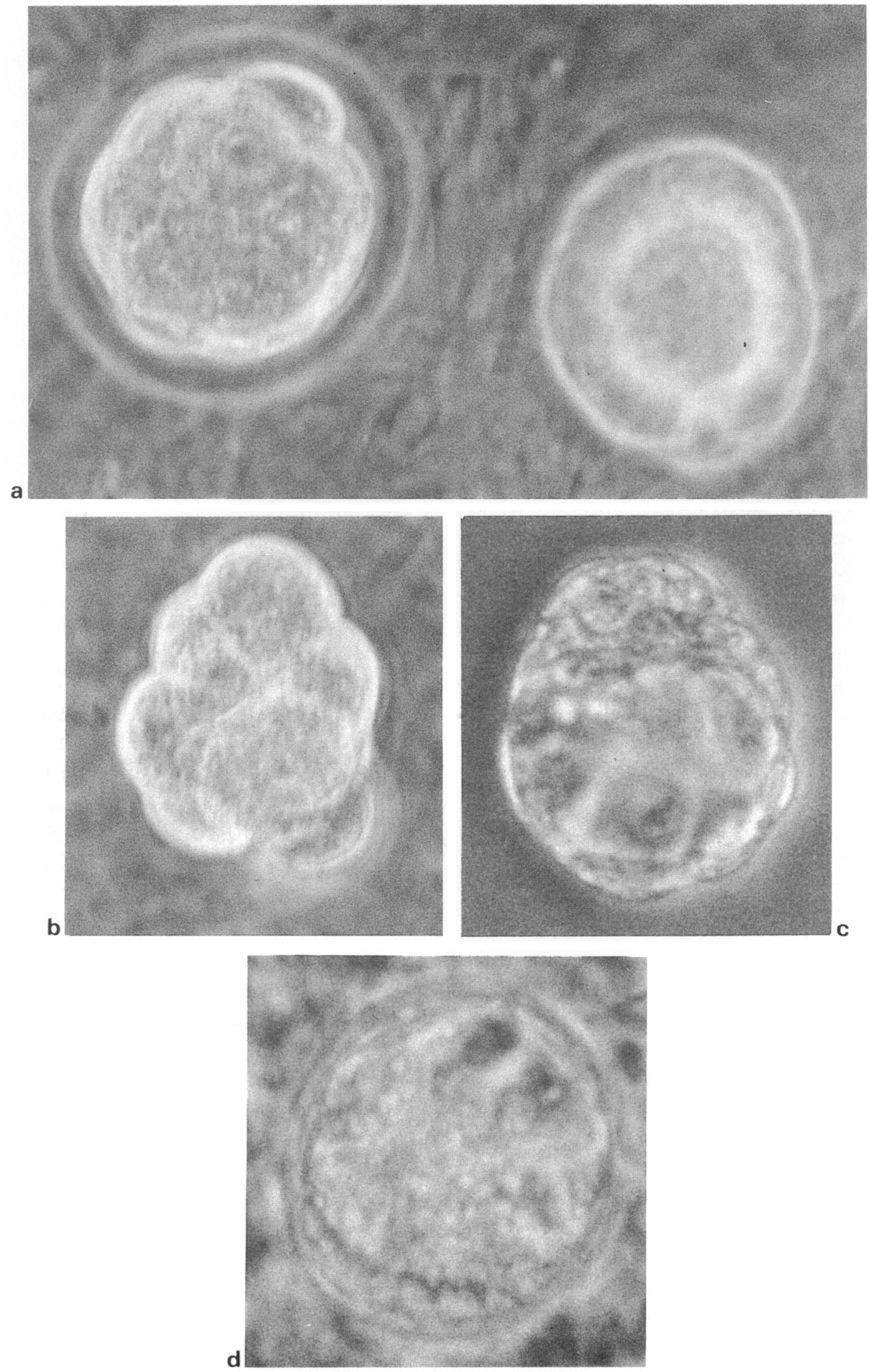

Fig. 1. Representative embryos, collected from mouse oviducts, which were treated and cultured in vitro. (a) Multiple encapsulated embryos ( 2 morulae) in a single alginate capsule. (b) Encapsulated zona pellucida-free embryo (compacted 8-cell) at $24 \mathrm{~h}$. (c) Zona pellucida-free embryo (early blastocyst) at $48 \mathrm{~h}$. (d) Encapsulated embryo (blastocyst) at $48 \mathrm{~h} . \times 400$. 
Sodium alginate offers the advantages of (1) the calcium-alginate matrix is biodegradable in the reproductive tract (Adinaya, 1987), and (2) the rate of biodegradation may be altered by changing the concentration of the alginate and/or calcium chloride solution.

Since most mammalian preimplantation embryos require a zona pellucida as protection during passage through the reproductive tract we tested an embedding material for deleterious effects on preimplantation mouse embryos and found none. We conclude that sodium alginate encapsulation is a viable means for supporting manipulated preimplantation embryos of the mouse.

We thank Mrs LaVonda Cleeves for typing the manuscript. This work was supported by grants ESO4911 and HDO7534 from the National Institutes of Health.

\section{References}

Adinaya, G.K. (1987) Development and evaluation of a microencapsulation process for use in in vitro fertilization. Master's thesis, Northwestern University, Evanston.

Adinaya, G.K., Rawlins, R.J., Miller, I.F. \& Zaneveld, L.J.D. (1987) Effects of sodium alginate encapsulation on the development of preimplantation mouse embryos. J. In Vitro Fertil. Embryo Transfer 4, 343-345.

Bavister, B.D., Leibfried, M.L. \& Leibfried, G. (1983) Development of preimplantation embryos of the golden hamster in a defined culture medium. Biol. Reprod. 28, 235-242.

Cholewa, J.A. \& Whitten, W.K. (1970) Development of two-cell mouse embryos in the absence of a fixednitrogen source. J. Reprod. Fert. 22, 553-555.

Cosby, N.C., Chou, K. \& Dukelow, W.R. (1989) Embryo production in B6D2Fl mice using two superovulating regimens. Lab. Anim. Sci. 39, 249-250.
Gill, J.L. (1978) Design and Analysis of Experiments in the Animal and Medical Sciences. vol. I. Iowa State University Press, Ames.

Hogan, B., Costantini, F. \& Lacy, E. (Eds) (1986) Manipulating the Mouse Embryo. Cold Spring Harbor Laboratory.

Lim, F. \& Sun, A.M. (1980) Microencapsulated islets as bio-artificial endocrine pancreas. Science, $N Y \mathbf{2 1 0}$, 908-910.

Warfield, S.J., Seidel, G.E. \& Elsden, R.P. (1987) Transfer of bovine demi-embryos with and without the zona pellucida. J. Anim. Sci. 65, 756-761.

Whittingham, D.G. (1971) Culture of mouse ova. $J$. Reprod. Fert., Suppl. 14, 7-21.

Willadsen, S.M. (1979) A method for culture of micromanipulated sheep embryos and its use to produce monozygotic twins. Nature, Lond. 277, 298-300.

Received 11 September 1989 